\title{
Association between ambient temperature and humidity, vaginal temperature, and automatic activity monitoring on induced estrus in lactating cows
}

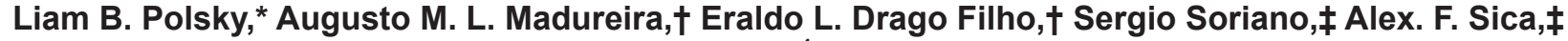 \\ José L. M. Vasconcelos, $†$ and Ronaldo L. A. Cerri*1 \\ *Applied Animal Biology, Faculty of Land and Food Systems, University of British Columbia, Vancouver, BC, Canada V6T 1Z4 \\ †Department of Animal Production, São Paulo State University, Botucatu, SP 18168-000, Brazil \\ $\ddagger$ Colorado Farm, Araras, Box 286, SP 13600-970, Brazil
}

\section{ABSTRACT}

The objective of this study was to determine the association between ambient temperature and humidity, vaginal temperature, and automated activity monitoring in synchronized cows. Lactating Holstein cows (n $=641 ; 41.5 \pm 9.4 \mathrm{~kg}$ of milk/d) were fitted with legmounted pedometers, resulting in 843 evaluated activity episodes of estrus. Vaginal temperature was monitored using thermometers attached to an intravaginal device as part of a timed artificial insemination (TAI) protocol; vaginal temperature was recorded every 10 min for $3 \mathrm{~d}$. Ambient temperature and relative humidity were monitored using an external thermometer placed in the center of each pen. Milk production and body condition score (BCS) data were collected at the time of thermometer insertion. All statistical analysis was performed in R (https://www.r-project.org/) using Pearson correlation, analysis of variance, and logistic regression. Heat stress was calculated based on the percentage of time the cow spent with a vaginal temperature $\geq 39.1^{\circ} \mathrm{C}$ (PCT39) 9 to $11 \mathrm{~d}$ before TAI, and was classified as high $(\geq 22.9 \%)$ or low $(<22.9 \%)$. The mean vaginal temperature was $38.9 \pm 0.2^{\circ} \mathrm{C}$, and the mean maximum and minimum vaginal temperatures were 39.7 $\pm 0.5^{\circ} \mathrm{C}$ and $38.0 \pm 0.8^{\circ} \mathrm{C}$, respectively, with an average amplitude of $1.71 \pm 0.9^{\circ} \mathrm{C}$. Mean relative increase (RI) of estrus walking activity was $237.0 \pm 160 \%$. Animals with low BCS had a lower RI compared with cows with medium BCS (260.31 $\pm 17.45 \%$ vs. $296.42 \pm 6.62 \%$ ). Cows in early lactation showed lower RI compared with mid- and late-lactation animals $(265.40 \pm 9.90 \%$ vs. $288.36 \pm 11.58 \%$ vs. $295.75 \pm 11.29 \%$ for early, mid, and late lactation, respectively). Temperature-humidity index (THI) conditions categorized as low (THI $\leq 65)$ were associated with greater RI compared with me$\operatorname{dium}(>65$ to $<70)$ and high THI $(\geq 70)$. We detected

Received January 28, 2017.

Accepted June 8, 2017.

${ }^{1}$ Corresponding author: ronaldo.cerri@ubc.ca no significant effect of PCT39 or milk production on RI, whereas parity exhibited a tendency. Cows that displayed greater RI at estrus had greater pregnancies per artificial insemination (P/AI) than cows with low RI (27 vs. $20 \%$ ) or no RI (27 vs. $12 \%$ ). Primiparous cows had greater P/AI than multiparous cows (27 vs. 20\%), and cows in early and mid lactation had improved $\mathrm{P}$ / AI than those in late lactation (26 vs. 22 vs. $16 \%$ for early, mid, and late lactation, respectively). An interaction was observed between PCT39 and THI on P/AI, where a subpopulation of cows with high PCT39 had decreased P/AI under high THI conditions, but no differences in P/AI were observed for high PCT39 cows under medium or low THI conditions (13 vs. 24 vs. $26 \%$ ). Future research should aim to refine variables related to hyperthermia and to understand the effects of body temperature on estrus expression and pregnancy rates.

Key words: heat stress, automated activity monitoring, estrus activity

\section{INTRODUCTION}

New precision dairy farming technologies allow for continuous monitoring of animal behaviors, which in turn can be used to improve herd health and reproductive management. Automated activity monitors (AAM) utilize behavioral increases in physical activity and restlessness displayed during estrus to detect estrus (Roelofs et al., 2010) and are suggested to predict ovulation timing (Roelofs et al., 2005; Stevenson et al., 2014). Recent research highlights estrus detection rates $>87 \%$ (Aungier et al., 2012), but can have a positive predictive value close to $90 \%$ depending on the detection system used (Madureira et al., 2015a). Moreover, AAM can capture the intensity of estrus behavior, which has a strong positive relationship with conception risk (Garcia et al., 2011; Madureira et al., 2015a). Automated activity monitors have been shown to improve estrus detection and conception rates compared with visual detection (Peralta et al., 2005) and can be 
integrated into timed AI protocols to select (cherrypick) animals as they come into heat (Burnett et al., 2017).

Environmental factors such as rain, wind speed, and ambient temperature and humidity can significantly affect the expression of estrus behavior (Roelofs et al., 2010). Global surface temperatures have increased by $0.2^{\circ} \mathrm{C}$ to $0.6^{\circ} \mathrm{C}$ since 2000 , and are projected to increase by $5.8^{\circ} \mathrm{C}$ by the end of the century (IPCC, 2007), increasing the concerns about heat stress faced by dairy producers. The thermoneutral zone of dairy cattle ranges from $5^{\circ} \mathrm{C}$ to $25^{\circ} \mathrm{C}$ when considering only dry bulb temperature. Within this temperature interval, the animal generates basal levels of metabolic heat and has minimal physiological costs to reach maximum milk production and achieve reproductive success (Kadzere et al., 2002). Heat stress is defined as the magnitude of high temperature forces, external to the body, that cause the animal to exceed its thermoneutral zone and induce coping mechanisms to avoid physiological dysfunction (Kadzere et al., 2002).

Heat-stressed cows have reduced milk production, DMI, and physical activity (De Rensis and Scaramuzzi, 2003; West, 2003; Schütz et al., 2008). Reproductive capabilities of dairy cattle are decreased as heat stress disrupts follicular development, steroidogenesis, oocyte quality, and embryo development (Pereira et al., 2015). One effect of heat stress on dairy reproduction is the lower percentage of cows detected in estrus (Thatcher and Collier, 1986) and lower conception to AI (Pereira et al., 2015). As a result, heat stress is responsible for annual economic losses to the US livestock production industry ranging from $\$ 1.69$ to $\$ 2.36$ billion, of which $\$ 900$ million is specific to the dairy industry (St-Pierre et al., 2003).

Vaginal temperature can be continuously monitored in dairy cows, allowing for the capture of the cow's diurnal circadian rhythm without subjecting the animal to stressful restraint procedures that can alter core temperatures. Reproductive tract temperature has direct implications on reproductive outcomes, as Gwazdauskas et al. (1973) first reported that a $0.5^{\circ} \mathrm{C}$ increase in uterine temperature decreased conception rates by 6.9 to $12.8 \%$. However, only a few studies have investigated the relationship between vaginal and environmental temperature events with estrus expression and subsequent fertility.

The objective of this research was to examine how vaginal or environmental temperature recorded 9 to 11d before breeding affects estrus activity in lactating dairy cows during induced estrus. We also investigated risk factors that could affect physical activity during estrus as well as pregnancy per AI (P/AI). We hypoth- esized that as vaginal or environmental temperatures increase, the expression of estrus walking behavior and $\mathrm{P} / \mathrm{AI}$ would decrease.

\section{MATERIALS AND METHODS}

\section{Location, Animals, and Diet}

This experiment was conducted from February 2014 to February 2015 on a commercial dairy farm located in Araras, São Paulo State, Brazil. The latitude, longitude, and altitude of the farm are $22.3605^{\circ} \mathrm{S}, 47.3798^{\circ} \mathrm{W}$, and $629 \mathrm{~m}$, respectively. At the time of the experiment, the herd had an average of 1,700 lactating cows and 305-d average yield of $11,438 \mathrm{~kg} /$ cow. Lactating Holstein cows ( $\mathrm{n}=641 ; 209$ primiparous, 432 multiparous) that were more than 50 DIM were enrolled onto this study on a weekly basis.

Cows were housed in a cross-ventilated freestall barn with grooved concrete floors. Cows were blocked in groups of 300 animals in pens with 2 rows of deep-bedded sand stalls (1 cow/stall). Milking was performed thrice daily (at approximately 0500, 1300, and $2100 \mathrm{~h}$ ) using a 72-stall rotary parlor. Cows were fed a TMR balanced to meet or exceed the nutritional requirements of lactating dairy cows producing $45 \mathrm{~kg} / \mathrm{d}$ of $3.5 \%$ FCM (NRC, 2001). Feed was delivered twice daily at approximately 0700 and $1600 \mathrm{~h}$ and pushed up 3 times/d. Water and TMR were available for ad libitum intake.

Cows were restrained in headlocks at the feed bunk after the morning milking during the performance of experimental procedures. All experimental procedures were approved by the local institutional animal care committee, following the requirements of the practices outlined in the Guide for the Care and Use of Agricultural Animals in Agricultural Research and Teaching (FASS, 1999).

\section{Measurement of Temperature-Humidity Index and Vaginal Temperature}

A humidity and temperature-measuring instrument (HOBO U23 Pro v2 Relative Temperature/Humidity Data Logger, Onset Computer Corp., Cape Cod, MA) was placed in a protected area closest to the bed or feed bunk in each pen, inside the barn. Temperature and humidity data were recorded every $10 \mathrm{~min}$ for 3 consecutive days. Software provided by the company (HOBOware, Onset Computer Corp.) was used to read the recorded temperature and humidity data. The temperature-humidity index (THI) was calculated following Mader et al. (2006): $\mathrm{THI}=\left(0.8 \times \mathrm{T}^{\circ} \mathrm{C}\right)+$ 
$\left[(\mathrm{RH} / 100) \times\left(\mathrm{T}^{\circ} \mathrm{C}-14.4\right)\right]+46.4$, where $\mathrm{T}=$ temperature and $\mathrm{RH}=$ relative humidity.

A temperature-recording data logger (Thermochron iButton, Lawrenceburg, KY) was coupled to an intravaginal progesterone implant (Eazi-Breed, Zoetis, São Paulo, Brazil), allowing the sensors to be in direct contact with the vaginal wall. The logger recorded vaginal temperature continuously every $10 \mathrm{~min}$ for $3 \mathrm{~d}$ (from to 9 to $11 \mathrm{~d}$ before timed AI (TAI).

Body condition score ( 1 to 5 scale in 0.25 increments; Wildman et al., 1982) and milk production (AfiMilk MPC milk meter, Afikim, Israel) were recorded at the time of thermometer insertion.

\section{Vaginal Temperature Analysis}

Different definitions of heat stress were screened to determine the most appropriate way to quantify heat stress: the total number of temperature bouts (number of episodes when the cow's body temperature exceeded $39.1^{\circ} \mathrm{C}$ ), peaks of highest temperature, temperature amplitude (the difference between the maximum and minimum recorded vaginal temperature), and total heat load (area under the curve for the total time and highest temperature episode greater than $39.1^{\circ} \mathrm{C}$ ) were calculated. There was no relationship between any of these variables and estrus intensity, $\mathrm{P} / \mathrm{AI}$, or THI (Table 1), and were not chosen to represent hyperthermia.

Hyperthermia was calculated based on the percentage of time the cow spent with a vaginal temperature $\geq 39.1^{\circ} \mathrm{C}$ (PCT39) 9 to $11 \mathrm{~d}$ before TAI. This measure was chosen to represent vaginal temperature because of the significantly negative relationship between relative increase (RI) and P/AI and because of lack of collinearity with THI.

\section{Reproductive Program and Pregnancy Diagnosis}

Following the expected voluntary waiting period of $55 \pm 5$ DIM, cows were enrolled into an ovulation synchronization protocol for first TAI and following negative pregnancy diagnoses.

Cows were presynchronized beginning at $32 \pm 6$ DIM using 2 injections of $25 \mathrm{mg}$ (i.m.) of $\mathrm{PGF}_{2 \alpha}$ (dinoprost tromethamine; Lutalyse, Zoetis, SP, Brazil) given 14 d apart. Cows were then synchronized based on the protocol described by Pereira et al. (2015): $11 \mathrm{~d}$ following the second $\mathrm{PGF}_{2 \alpha}$ injection of the presynchronization, cows initiated the following synchronization protocol: at $\mathrm{d}-11$ : intravaginal progesterone implant (Eazi-Breed controlled internal drug-releasing implant containing $1.9 \mathrm{mg}$ of progesterone, Zoetis) $+2.0 \mathrm{mg}$ (i.m.) of estradiol benzoate (Gonadiol, Zoetis) $+100 \mu \mathrm{g}$ (i.m.) of gonadotropin-releasing hormone (gonadorelin diacetate; Cystorelin, Merial, SP, Brazil); at d -4: 25 $\mathrm{mg}$ (i.m.) of $\mathrm{PGF}_{2 \alpha}$ (dinoprost tromethamine; Lutalyse, Zoetis); at $\mathrm{d}-2$ : removal of intravaginal progesterone insert $+1.0 \mathrm{mg}$ (i.m.) of estradiol cypionate (ECP, E.C.P., Zoetis) + $25 \mathrm{mg}$ (i.m.) of $\mathrm{PGF}_{2 \alpha}$; and at d 0: TAI performed using commercial semen from 10 randomly selected bulls.

Positive pregnancy diagnosis was made when an amniotic vesicle with viable embryo was detected via rectal palpation with ultrasonography (Honda HS 101V with a 5.0-MHz linear probe, Honda, Tokyo, Japan) 32 and $60 \mathrm{~d}$ after TAI.

\section{AAM Data}

All cows were equipped with a pedometer (Afimilk Pedometer Plus Tag, AfiMilk, Kibbutz Afikim, Israel)

Table 1. Pearson correlation coefficients showing the relationship between relative increase (RI) and temperature-humidity index (THI) and explored metrics of vaginal temperature, recorded 9 to $11 \mathrm{~d}$ before breeding

\begin{tabular}{|c|c|c|c|c|c|c|}
\hline Item & RI & THI & PCT39 & Temp. Bouts & Temp. Peaks $\left({ }^{\circ} \mathrm{C}\right)$ & Temp. Amp. $\left({ }^{\circ} \mathrm{C}\right)$ \\
\hline $\begin{array}{l}\text { THI }^{2} \\
{\text { PCT } 39^{3}}\end{array}$ & $\begin{array}{l}-0.16^{\text {*ศर }} \\
-0.10^{*}\end{array}$ & $0.30 * * *$ & & & & \\
\hline Temp. Peaks ${ }^{5}$ & $-0.09^{*}$ & $0.28^{* * *}$ & $0.71^{* * *}$ & $0.30^{* * *}$ & & \\
\hline Temp. Amp. ${ }^{6}$ & -0.04 & $0.17^{* * *}$ & $0.22 * * *$ & $0.14^{* * *}$ & $0.50^{* * *}$ & \\
\hline Heat load ${ }^{7}$ & $-0.10^{* *}$ & $0.29 * * *$ & $0.87^{* * *}$ & $0.15^{* * *}$ & $0.76^{* * *}$ & $0.26^{* * *}$ \\
\hline
\end{tabular}

${ }^{1}$ Calculated as [(induced estrus steps/h - baseline steps $\left./ \mathrm{h}\right) /$ baseline steps $\left./ \mathrm{h}\right] \times 100$.

${ }^{2} \mathrm{THI}$ calculated as $\left(0.8 \times \mathrm{T}^{\circ} \mathrm{C}\right)+\left[(\mathrm{RH} / 100) \times\left(\mathrm{T}^{\circ} \mathrm{C}-14.4\right)\right]+46.4$, where $\mathrm{T}=$ temperature and $\mathrm{RH}=$ relative humidity $(\mathrm{Mader}$ et al., 2006).

${ }^{3} \mathrm{PCT} 39=$ percentage of time $(\min ) 9$ to $11 \mathrm{~d}$ before breeding when the cow's vaginal temperature was $\geq 39.1^{\circ} \mathrm{C}$.

${ }^{4}$ Number of episodes when the cow's body temperature exceeded $39.1^{\circ} \mathrm{C}$.

${ }^{5}$ Peaks of highest temperature when the cow's body temperature exceeded $39.1^{\circ} \mathrm{C}$.

${ }^{6}$ Temperature amplitude: difference between the maximum and minimum recorded vaginal temperature.

${ }^{7}$ Area under the curve for the total time and highest temperature episode greater than $39.1^{\circ} \mathrm{C}$.

${ }^{*} P<0.5,{ }^{* *} P<0.01,{ }^{* * *} P<0.001$. 


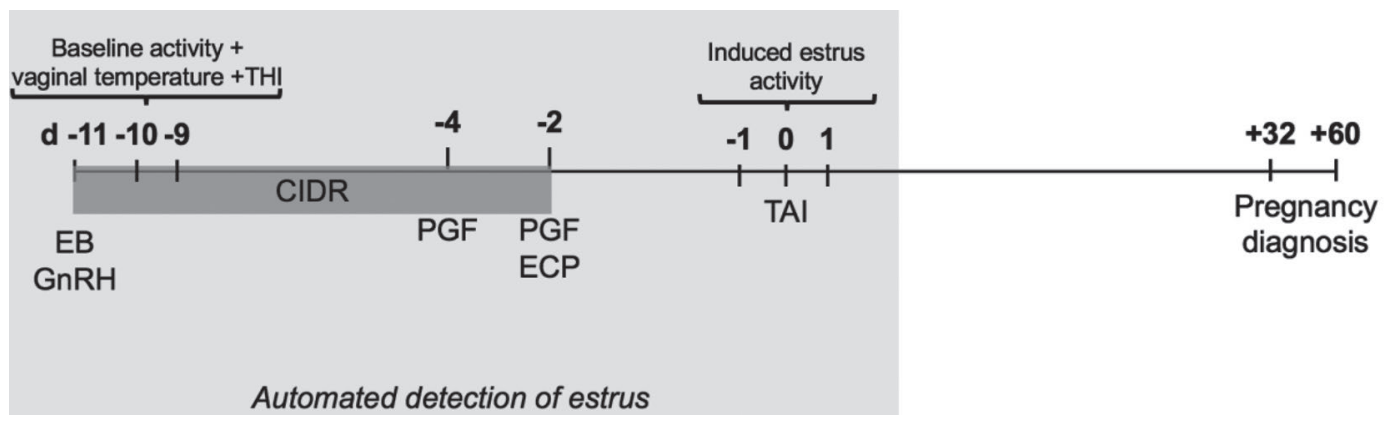

Figure 1. Schematic of the experimental estrus synchronization protocol as redrawn from Pereira et al. (2015). Automated detection of estrus was done with Afimilk Pedometer Plus Tags and AfiFarm software (Afimilk, Kibbutz Afikim, Israel). EB = estradiol benzoate (2 mg, Gonadiol, Zoetis, São Paulo, Brazil), GnRH = gonadorelin diacetate $(100 \mu \mathrm{g}$, Cystorelin, Merial, São Paulo, Brazil), PGF = PGF $2 \alpha($ dinoprost tromethamine, $25 \mathrm{mg}$, Lutalyse, Zoetis), ECP = estradiol cypionate, $1 \mathrm{mg}$, E.C.P., Zoetis), CIDR = intravaginal progesterone implant (1.9 mg of progesterone; CIDR, Zoetis), and TAI = timed AI. Relative increase was calculated as follows: $\{$ induced estrus steps $(\mathrm{d}-1, \mathrm{~d} 0, \mathrm{~d} 1) / \mathrm{h}-$ baseline steps/h (mean d $-11, \mathrm{~d}-10, \mathrm{~d}-9)] /$ baseline steps $/ \mathrm{h}\} \times 100$.

that was attached to one of the hind limbs within $1 \mathrm{wk}$ of calving. Data were wirelessly transferred from tags to a database every $8 \mathrm{~h}$ in blocks of $2 \mathrm{~h}$. Data were retrieved from AfiFarm Dairy Farm Management Software (AfiMilk) and compiled using Excel (Microsoft Corp., Redmond, WA).

Walking behavior was recorded on a 24 -h basis and averaged into three 8-h sessions/d (0000 to 0759 h, 0800 to $1559 \mathrm{~h}$, and 1600 to $2359 \mathrm{~h}$ ). Walking activity during induced estrus was calculated from the 8-h session with the greatest number of steps on $\mathrm{d}-1, \mathrm{~d} 0$, and $\mathrm{d} 1$. Baseline steps/hour were calculated from the average of the 8-h session with the greatest number of steps on the $\mathrm{d}-11, \mathrm{~d}-10$, and $\mathrm{d}-9$ sessions (Figure 1).

\section{Statistical Analysis}

This experiment was an observational cohort study, with 843 estrus walking events recorded $(\mathrm{n}=641,1.3 \pm$ 0.6 estrus events/animal). All statistical analyses were performed using R statistical software (version 0.99.903; Boston, MA). Descriptive statistics and normality tests were obtained using the STATS package (R Core Team, 2016). Normality was visually assessed using Q-Q plots and confirmed using the Shapiro-Wilks test. Classified variables used for analysis are described below. Milk production was classified into high or low based on the median production $(41.5 \mathrm{~kg} / \mathrm{d})$. Lactation stage at thermometer insertion was classified by DIM: early $(\leq 100$ DIM), mid $(>100$ to $<180$ DIM $)$, and late $(\geq 180$ DIM) lactation. Parity was divided into cows in first lactation or second lactation and higher (primiparous vs. multiparous). Body condition score was classified as low $(\leq 2.50)$, medium $(=2.75)$, and high $(\geq 3.00)$.

The RI of an estrus walking episode was calculated from induced estrus activity and baseline activity (steps/h) using the calculation [(induced estrus steps/h - baseline steps $/ \mathrm{h}) /$ baseline steps $/ \mathrm{h}] \times 100$. The RI was categorized as no heat $(\leq 69 \%$; no estrus expression) and RI expression of low intensity (70 to 200\%) or high intensity $(\geq 200 \%)$. This threshold for estrus intensity was obtained from previous research from our group (Madureira et al., 2015b), where a significant improvement in $\mathrm{P} / \mathrm{AI}$ was observed in association with a relative increase in walking activity $\geq 200 \%$ at estrus. Temperature-humidity index was classified as low $(\leq 65)$, medium $(65-70)$, and high $(\geq 70)$ by dividing THI data into 33rd percentiles. Continuous vaginal temperature data were transformed into new class variables; PCT39 was classified as high or low (median: $22.9 \%$; high $\geq 22.90 \%$; low $<22.90 \%$ ).

Pearson correlation coefficients and significance levels were calculated for the relationships between animal measurements (BCS, DIM, milk yield, parity, and PCT39), automatic measurements (RI), and environmental measurements (THI) using the HMISC package (Frank and Dupont, 2016). Continuous data were analyzed by ANOVA using the lme4 package (Bates et al., 2015). The outcome variable was RI, and the model's fixed effects included milk production, parity, DIM, BCS, PCT39, and THI, with cow as a random effect.

The $\mathrm{P} / \mathrm{AI}$ was calculated by dividing the number of pregnant cows at the pregnancy diagnosis at d 32 after TAI by the total number of cows that received TAI. The $\mathrm{P} / \mathrm{AI}$ was evaluated by logistic regression using the GLM package in $\mathrm{R}$ ( $\mathrm{R}$ Core Team, 2016). The model built by the logistical regression included the fixed effects of RI, milk production, DIM, parity, BCS, and PCT39. Using backward stepwise elimination, variables were removed from the model using the Wald statistic criterion $(P>0.15)$. Significance was set at $P<0.05$ and $0.05<P<0.10$ was considered a tendency. 


\section{RESULTS}

\section{Vaginal and Environmental Temperature}

The mean vaginal temperature during the 3 -d recording period from d 11 to 9 before AI was $38.9 \pm 0.24^{\circ} \mathrm{C}$, with mean maximum and minimum temperatures of $39.7 \pm 0.46^{\circ} \mathrm{C}$ and $38.0 \pm 0.75^{\circ} \mathrm{C}$, respectively. The average vaginal temperature amplitude was $1.70 \pm$ $0.87^{\circ} \mathrm{C}$. The mean PCT39 was $27.6 \pm 23.1 \%$, with a quartile (Q)1 and Q3 distribution of 8.5 and $40.8 \%$, respectively. The mean calculated THI during the hot season was $68.9 \pm 2.9$, with maximum and minimum values of 73.8 and 61.5 , respectively. The mean calculated THI during the wet season was $64.3 \pm 2.0$, with maximum and minimum values of 68.3 and 61.0 , respectively. The Pearson correlation coefficient between PCT39 and THI was $0.32(P<0.001)$. The maximum vaginal temperature and amplitude were weakly correlated with THI $(\mathrm{r}=0.28, P<0.001$; and $\mathrm{r}=0.17, P$ $<0.001$, respectively).

\section{Animals and Description of Estrus Events}

The AAM detected 843 estrus events. Estrus events were considered as "true" if the RI exceeded $70 \%$. Only true estrus events were used for the analyses of risk factors affecting RI. All 843 estrus events were followed by $\mathrm{AI}$ and subsequent pregnancy diagnosis performed on d 32 after AI and again on d 60 if previously diagnosed pregnant. Cows that were not diagnosed pregnant at $\mathrm{d}$ 32 or d 60 were re-enrolled into the identical protocol. The mean RI recorded by the monitors was $237.4 \pm$ $160.1 \%$ and the mean baseline activity was $198.5 \pm$ $71.5 \mathrm{steps} / \mathrm{h}$. The average milk production was 41.5 $\pm 9.4 \mathrm{~kg} /$ cow per day. At the time of data collection, the mean DIM was $164.3 \pm 105.9 \mathrm{~d}$. The percentage of animals submitted for first, second, and third TAI were $26 \%(214 / 834), 19 \%(158 / 834)$, and $55 \%$ (462/843), respectively.

\section{Factors Affecting RI of Estrus Expression}

Body condition score had a marked association with estrus walking activity, as animals with a low BCS had a lower RI than animals with a medium BCS $(P<$ 0.05 ; Table 2). The DIM at the time of estrus affected RI as cows in early of lactation $(<100$ DIM) showed lower RI than mid- and late-lactation animals $(P<$ 0.05 ; Table 2$)$. Lower THI values $(\leq 65)$ were associated with greater RI compared with medium $(>65$ to $<70)$ and high THI ( $\geq 70 ; P<0.01$; Table 2$)$, respectively. Univariable analysis showed effects of THI on PCT39
Table 2. Least squares means $( \pm \mathrm{SE})$ for peak relative increase $(\mathrm{RI}$ $\%$ ) according to BCS, DIM, temperature-humidity index (THI), PCT39, milk production, and parity

\begin{tabular}{ll}
\hline Parameter & Peak RI \\
\hline BCS $^{2}$ & \\
Low $(<2.75)$ & $260.31 \pm 17.45^{\mathrm{a}}$ \\
Medium $(=2.75)$ & $296.42 \pm 6.62^{\mathrm{b}}$ \\
High $(\geq 3)$ & $292.86 \pm 12.32^{\mathrm{ab}}$ \\
DIM & \\
Early $(\leq 100)$ & $265.40 \pm 9.90^{\mathrm{a}}$ \\
Mid $(100-180)$ & $288.36 \pm 11.58^{\mathrm{b}}$ \\
Late $(\geq 180)$ & $295.75 \pm 11.29^{\mathrm{b}}$ \\
THI & \\
Low $(\leq 65)$ & $313.26 \pm 10.59^{\mathrm{a}}$ \\
Medium $(65-70)$ & $276.18 \pm 11.02^{\mathrm{b}}$ \\
High $(\geq 70)$ & $260.06 \pm 10.76^{\mathrm{b}}$ \\
PCT39 & \\
High $(\geq 22.90 \%)$ & $284.12 \pm 9.55^{\mathrm{a}}$ \\
Low $(<22.90 \%)$ & $286.08 \pm 18.42^{\mathrm{a}}$ \\
Milk production & \\
High $(\geq 41.50 \mathrm{~kg} / \mathrm{d})$ & $282.12 \pm 15.66^{\mathrm{a}}$ \\
Low $(<41.50 \mathrm{~kg} / \mathrm{d})$ & $288.09 \pm 13.99^{\mathrm{a}}$ \\
Parity & \\
Primiparous & $291.41 \pm 13.47^{\mathrm{a}}$ \\
Multiparous & $278.80 \pm 13.47^{\mathrm{a}}$ \\
\hline
\end{tabular}

${ }^{\mathrm{a}, \mathrm{b}}$ Different letters within a parameter indicate a significant difference $(P<0.05)$. Significance was set at $P<0.05$, and $0.05<P<0.10$ was a tendency.

${ }^{1}$ Calculated as $[($ induced estrus steps $/ \mathrm{h}$ - baseline steps $/ \mathrm{h}) /$ baseline steps/h] $\times 100$.

${ }^{2} \mathrm{BCS}$ was classified based on 1 to 5 scale at 0.25 increments (Wildman et al., 1982).

${ }^{3} \mathrm{THI}$ was classified as low $(\leq 65)$, medium $(>65$ to $<70)$, and high $(\geq 70)$ and calculated as $\left(0.8 \times \mathrm{T}^{\circ} \mathrm{C}\right)+\left[(\mathrm{RH} / 100) \times\left(\mathrm{T}^{\circ} \mathrm{C}-14.4\right)\right]+$ 46.4, where $\mathrm{T}=$ temperature and $\mathrm{RH}=$ relative humidity.

${ }^{4}$ Percentage of time ( $\mathrm{min}$ ) when the cow's vaginal temperature was $\geq 39.1^{\circ} \mathrm{C}$ measured 9 to 11 d before breeding. High: $\geq 22.90 \%$; Low $<22.90 \%$.

$(P<0.02 ;$ Figure 2A). Univariable analyses showed effects of PCT39 $(P<0.02$; Figure $2 \mathrm{~B})$ and THI $(P$ $<0.01$; Figure 2C) on RI, but when THI was included in the model, PCT39 became insignificant $(P<0.79$; Table 2). Both PCT39 and THI were included in the model because they were weakly correlated $(\mathrm{r}=0.32$; $P<0.001)$. Milk production had no effect $(P<0.13$; Table 2) on RI, whereas parity demonstrated a tendency $(P<0.06$; Table 2$)$.

\section{Risk Factors for P/AI}

The P/AI was strongly associated with RI expression, as well as RI intensity. Cows that expressed high RI compared with no RI had greater P/AI (27 vs. $12 \%$; $P<0.01$; Table 3). Cows that expressed low RI compared with no RI had greater P/AI (20 vs. $12 \%$; $P<$ 0.017; Table 3). Animals that expressed more intense RI were more fertile than animals exhibiting low RI intensity (27 vs. 20\%; $P<0.05$; Table 3). Primiparous 


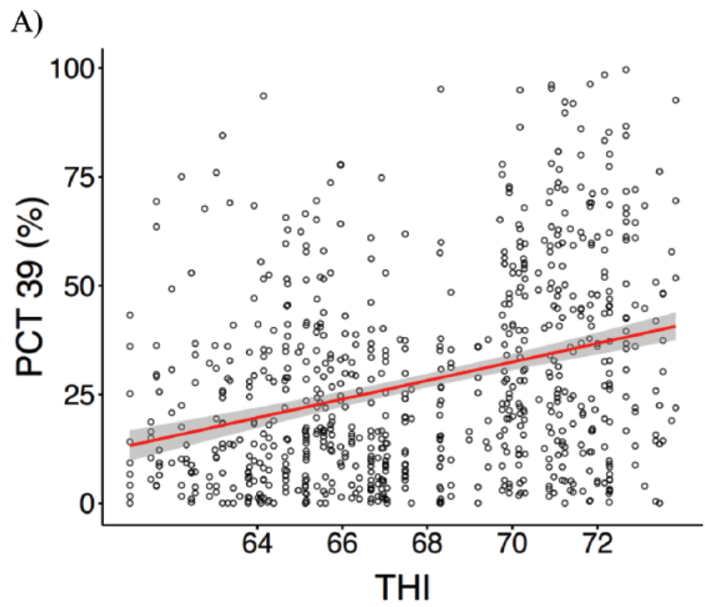

B)

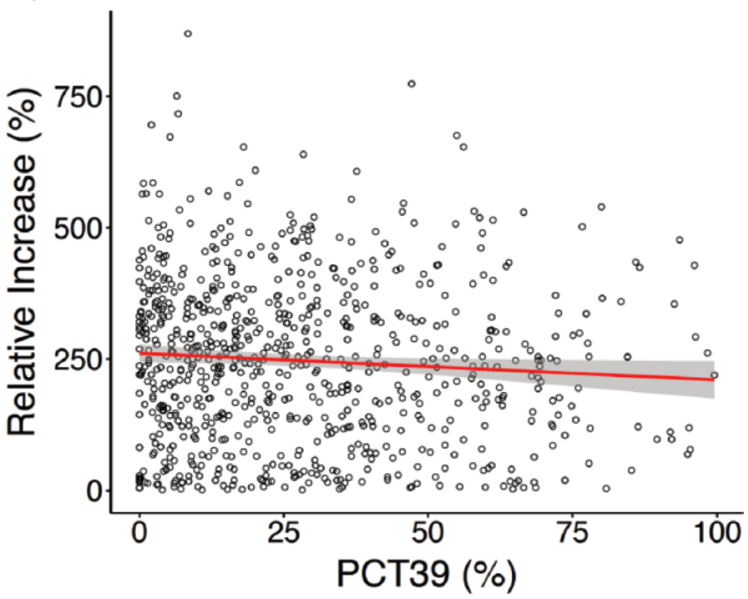

C)

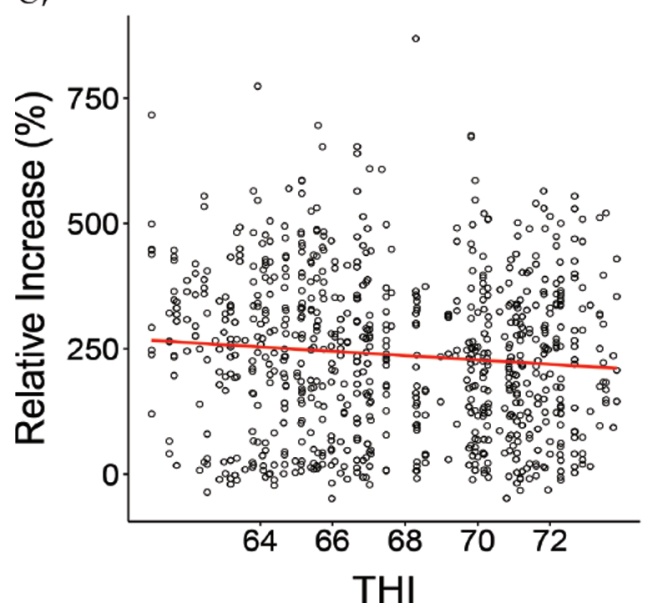

Figure 2. Pearson correlation coefficients between (A) temperature-humidity index (THI) and percentage of time (min) 9 to 11 $\mathrm{d}$ before breeding when the cow's vaginal temperature was $\geq 39.1^{\circ} \mathrm{C}$ (PCT39; $P<0.03 ; \mathrm{r}<0.01$ ); (B) PCT39 and relative increase in walking activity $(P<0.02 ; \mathrm{r}<0.01)$; and $(\mathrm{C})$ THI and relative increase in walking activity $(P<0.009 ; \mathrm{r}<0.01)$. THI was calculated as $(0.8 \times$ $\left.\mathrm{T}^{\circ} \mathrm{C}\right)+\left[(\mathrm{RH} / 100) \times\left(\mathrm{T}^{\circ} \mathrm{C}-14.4\right)\right]+46.4$, where $\mathrm{T}=$ temperature and $\mathrm{RH}=$ relative humidity (Mader et al., 2006); relative increase was calculated as [(induced estrus steps/h - baseline steps/h)/baseline steps $/ \mathrm{h}] \times 100$. The shaded area represents the $95 \% \mathrm{CI}$ of the regression analysis. Color version available online. cows had greater $\mathrm{P} / \mathrm{AI}$ compared with multiparous cows (27 vs. $20 \% ; P<0.03$; Table 3 ). The DIM at the time of AI affected $\mathrm{P} / \mathrm{AI}$, as cows in early lactation had better $\mathrm{P} / \mathrm{AI}$ than those in mid and late lactation (26 vs. 22 vs. $16 \% ; P<0.01$; respectively; Table 3 ). An interaction was observed between PCT39 and THI on $\mathrm{P} / \mathrm{AI}(P<0.03$; Figure 3$)$, where a subpopulation of cows with high PCT39 had decreased P/AI under high THI conditions, but no differences in $\mathrm{P} / \mathrm{AI}$ were observed for high PCT39 cows under medium and low THI conditions ( 13 vs. 24 vs. $26 \% P<0.01$; Figure 3 ). Pregnancies per AI was not influenced by BCS $(P=$ $0.90)$ or milk yield $(P=0.82)$. There was no interaction between PCT39 and RI expression on P/AI $(P=0.76$; Figure 4) or between THI and PCT39 on RI expression $(P=0.14 ;$ Figure 5$)$.

\section{DISCUSSION}

In the current study, we assessed the effects of vaginal temperature and other risk factors on the RI of estrus walking behavior, as well as P/AI, in lactating dairy cows. We assessed the animal's experience of heat stress by examining the percentage of time that vaginal temperature $\geq 39.1^{\circ} \mathrm{C}$, but found no association with estrus RI when including THI in our statistical model. We found an interesting interaction between PCT39 and THI on P/AI by identifying a subgroup of animals that maintained high PCT39 and low P/AI under high THI conditions.

One of the objectives of this paper was to determine the best way to quantify the animal's experience of heat stress and how heat load is related to the expression of estrus walking behavior and fertility. A vaginal thermometer is a noninvasive method that allows body temperature to be continuously recorded without subjecting the animal to stressful restraint procedures that can also influence body temperature. Within our data set, different metrics of temperature variation at varying thresholds were examined, including temperature bouts (number of episodes when the cow's body temperature exceeded $39.1^{\circ} \mathrm{C}$ ), peaks of highest temperature, temperature amplitude, and total heat load (area under the curve for the total time and highest temperature episode greater than $39.1^{\circ} \mathrm{C}$ ). Ultimately, PCT39 was chosen as the most functional measurement to represent heat stress due to its ability to quantify interactions between environmental stressors and activity measurements. This measurement agrees with the findings of Vasconcelos et al. (2011) during an embryo transfer experiment. Future research should continue to examine ways to explore continuous temperature measurements that quantify heat stress and incorporate 
Table 3. Odds ratio $\pm 95 \%$ CI for pregnancy per AI (\%) according to milk yield, BCS, relative increase (RI), DIM, and parity

\begin{tabular}{lccrc}
\hline Parameter & $\begin{array}{c}\text { Odds } \\
\text { ratio }\end{array}$ & $95 \%$ CI & $P$-value $^{1}$ & $\begin{array}{c}\text { Pregnancy per AI } \\
\text { (\%; no./no.) }\end{array}$ \\
\hline Milk yield $^{2}$ (low vs. high) & 1.03 & $0.70-1.54$ & 0.82 & $25(103 / 408) ; 19(77 / 397)$ \\
BCS $^{3}$ (medium vs. low) & 1.1 & $0.54-2.25$ & 0.33 & $20(33 / 163) ; 20(19 / 96)$ \\
BCS (high vs. medium) & 1.12 & $0.69-1.81$ & 0.65 & $23(128 / 547) ; 20(33 / 163)$ \\
RI $^{4}$ (high vs. no heat) & 2.87 & $1.73-4.80$ & $<0.01$ & $27(124 / 455) ; 12(21 / 174)$ \\
RI (high vs. low) $_{\text {DIM }^{5} \text { (late vs. early) }}^{1.54}$ & $0.99-2.42$ & 0.05 & $27(124 / 455) ; 20(35 / 177)$ \\
DIM (late vs. mid) $_{\text {Parity }^{6} \text { (multi vs. primi) }}$ & 0.44 & $0.28-0.70$ & $<0.01$ & $16(35 / 220) ; 26(95 / 363)$ \\
& 0.58 & $0.35-0.96$ & $<0.01$ & $16(35 / 220) ; 22(50 / 223)$ \\
\hline
\end{tabular}

${ }^{1}$ Significance was set at $P<0.05$, and $0.05<P<0.10$ was a tendency.

${ }^{2}$ Median $=41.50 \mathrm{~kg} / \mathrm{d}$.

${ }^{3}$ Low: $<2.75$, medium: 2.75 , high: $\geq 3$.

${ }^{4}$ Relative increase in activity, where no heat: $\leq 69 \%$, low intensity: $70-200 \%$, high intensity: $\geq 200 \%$. RI is calculated as [(induced estrus steps/h - baseline steps/h)/baseline steps/h] × 100 .

${ }^{5}$ Early: $\leq 100$ DIM, mid: $100-180$ DIM, late: $\geq 180$ DIM.

${ }^{6}$ Primi $=$ first lactation $;$ multi $=$ second lactation and higher.

the animal's individual daily variation and basal body temperatures.

Our results did not show a significant effect of BCS or milk production on $\mathrm{P} / \mathrm{AI}$ and do not support the general literature, which has shown an association between increased milk production and reduced fertility (Walsh et al., 2011; Burnett et al., 2014). However, BCS was a major risk factor for RI at estrus, as animals with low BCS had a lower overall RI at estrus. Our study supports conclusions by Madureira et al. (2015a), who found that animals with low BCS had less intense estrus behavior measured by 2 separate AAM, and by Løvendahl and Chagunda (2010), who noted that low postpartum BCS had a negative correlation with estrus activity. Aungier et al. (2012) provided additional evidence by showing that a 0.25 -point increase in BCS at estrus increased the odds of a cow to display high activity by 1.38 . Following parturition, nutrient requirements shift to support the increased demand for milk production, and the resulting state of negative energy balance (NEB) can last 10 to $12 \mathrm{wk}$ (Butler, 2003). This NEB is associated with reductions in ovarian cyclicity and reproductive functioning via suppressed pulsatile LH secretion, ovarian sensitivity

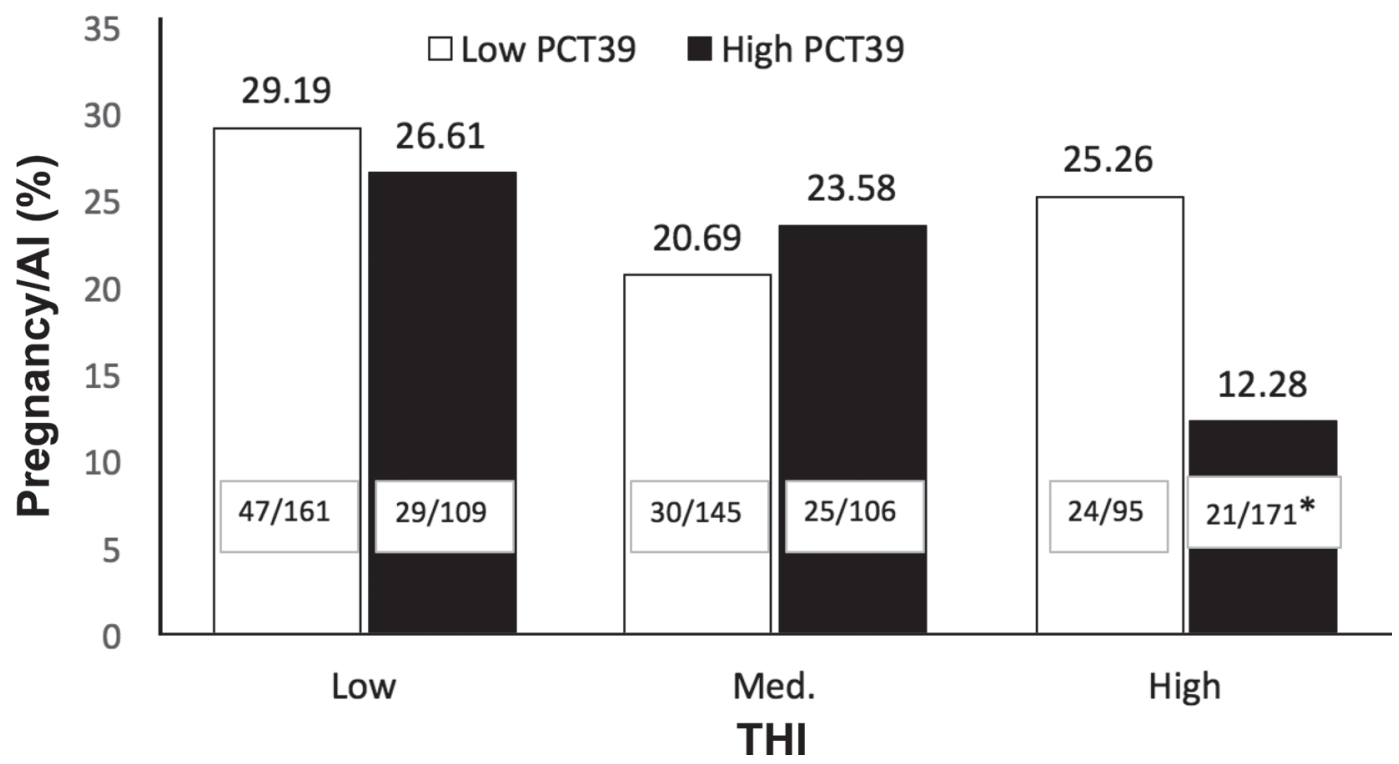

Figure 3. Distribution of pregnancy per AI (\%) according to the interaction between temperature-humidity index (THI) and percentage of time (min) 9 to $11 \mathrm{~d}$ before breeding when the cow's vaginal temperature was $\geq 39.1^{\circ} \mathrm{C}$ (PCT39). THI was classified as low $(\leq 65)$, medium (65-70), or high ( $\geq 70)$; PCT39 was classified as high $(\geq 22.90 \%$; black bars) or low $(<22.90 \%$; white bars $)(* P<0.03)$. 


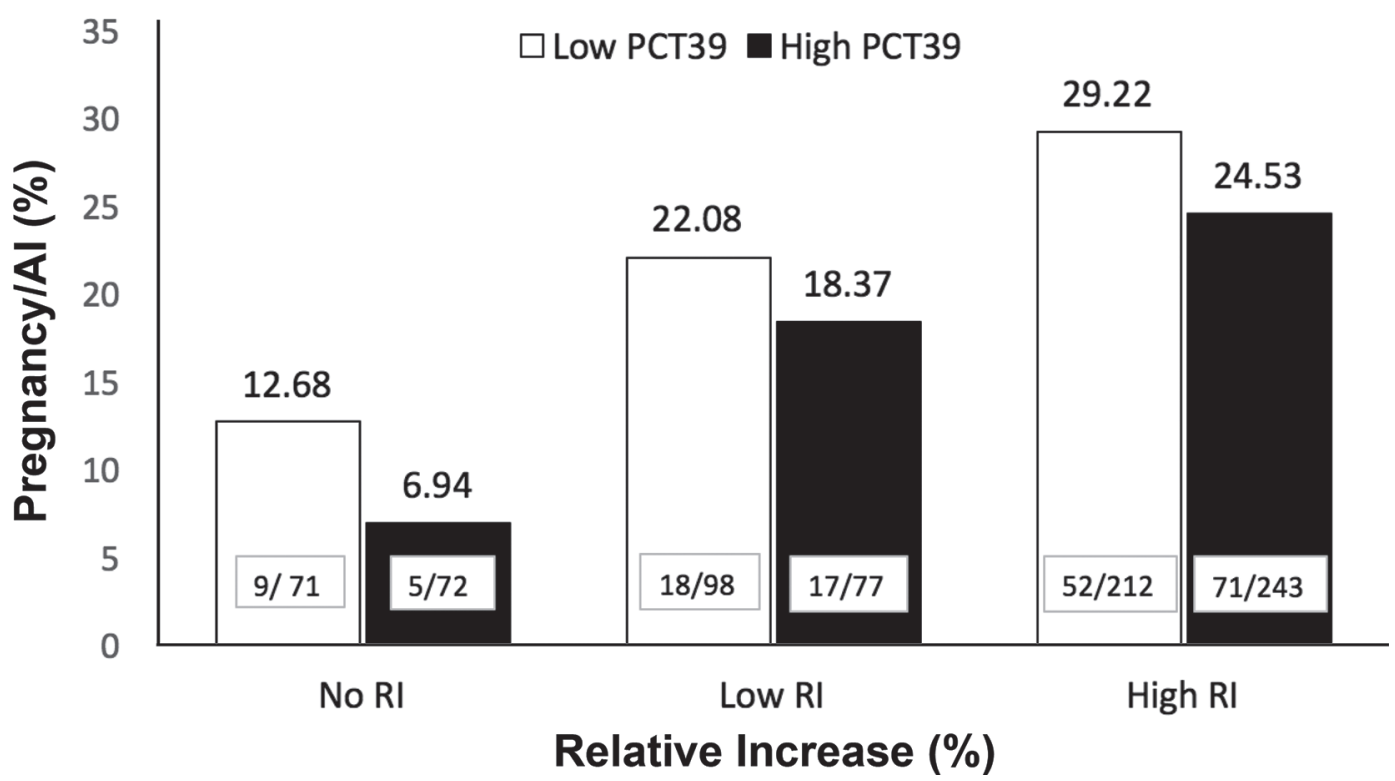

Figure 4. Distribution of pregnancy per AI (\%) according to the interaction between relative increase (RI) and percentage of time (min) 9 to $11 \mathrm{~d}$ before breeding when the cow's vaginal temperature was $\geq 39.1^{\circ} \mathrm{C}$ (PCT39). PCT39 was classified as high ( $\geq 22.90 \%$; black bars) or low $(<22.90 \%$; black bars); RI was calculated as [(induced estrus steps $/ \mathrm{h}-$ baseline steps $/ \mathrm{h}) /$ baseline steps $/ \mathrm{h}] \times 100$, and classified as no heat $(\leq$ $69 \%)$, low intensity $(70-200 \%)$, or high intensity $(\geq 200 \%)(P<0.76)$.

to LH (Butler, 2000), and reduced plasma insulin and IGF-1 (Butler, 2003). We speculate that decreases in BCS, and the subsequent NEB, can decrease estrus activity of lactating dairy cows through an impaired endocrine-nutritional pathway. Future research should aim to elucidate the specific mechanism by which NEB decreases estrogen-dependent estrus behavior in dairy cows.

Our results indicate that cows in later stages of lactation will have higher RI at estrus compared with

$\square$ Low PCT39 $\quad$ High РCT39

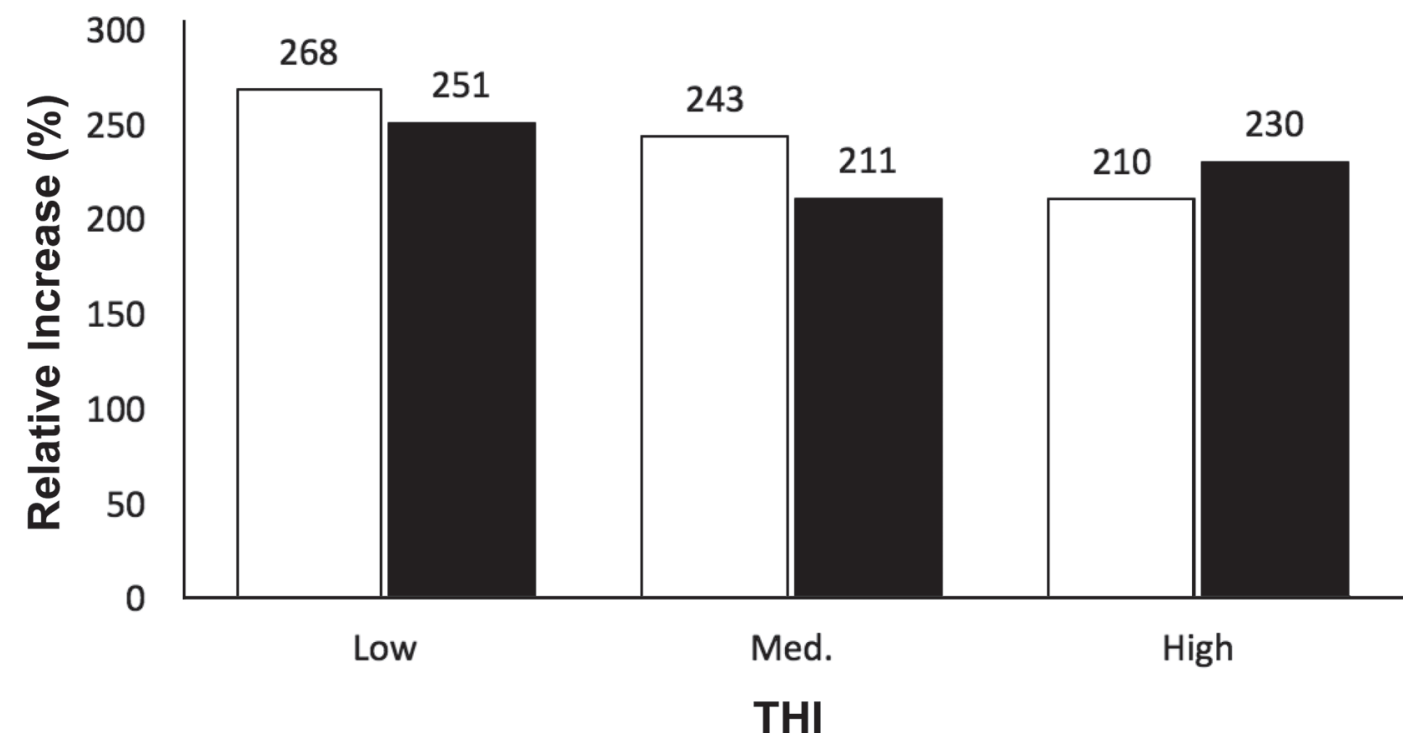

Figure 5. Distribution of relative increase (RI; \%) according to the interaction between temperature-humidity index (THI) and percentage of time (min) 9 to $11 \mathrm{~d}$ before breeding when the cow's vaginal temperature was $>39.1^{\circ} \mathrm{C}$ (PCT39). RI was calculated as [(induced estrus steps/h - baseline steps/h)/baseline steps/h] $\times 100$; THI was classified as low $(\leq 65)$, medium $(65-70)$, or high $(\geq 70)$; and PCT39 was classified as high $(\geq 22.90 \%$; black bars $)$ or low $(<22.90 \%$; white bars $)(P<0.14)$. 
animals at earlier DIM. Our results are supported by Madureira et al. (2015a) but not by López-Gatius et al. (2005), who found no significant relationship between stage of lactation and estrus activity. One explanation for the differing results might be the classification of lactation stage used between studies. López-Gatius et al. (2005) categorized animals as early (50-90), mid (91-150), and late (>150) DIM, which was based on nutritional status and subsequent energy balance. Our categorized classes for DIM were early $(\leq 100)$, mid $(>100$ to $<180)$ and late $(\geq 180)$ DIM and were established based on when the cows were enrolled into the reproductive protocol. We speculate that cows in later stages of lactation will have a lower metabolic challenge and can express more intense estrus. Following the first estrus episode after puberty, heifer estrus expression will continually increase in intensity (Silper et al., 2015). We speculate that the absence of progesterone during the first cycle postpartum (cows) and before the onset of puberty (heifers) is responsible for decreased estrus intensity.

This study found that the vaginal temperature recorded 9 to $11 \mathrm{~d}$ before induced estrus does not influence the expression of walking RI. Although the delayed effects of heat stress on follicular growth (Wolfenson et al., 2000), P/AI (Pereira et al., 2013), and successful embryo transfer (Demetrio et al., 2007) have been well documented, the findings of the current study suggest that the effects of heat stress do not have acute carry-over effects on estrus behavior. This is an interesting observation because research has shown that cows that were previously heat stressed had decreased plasma estradiol and inhibin, resulting in increased FSH concentrations compared with nonheat-stressed cows during the following follicular wave (Roth et al., 2000). Further research is required to elucidate the complex interaction between heat-stressed follicles, estradiol production, and walking behavior at estrus. Our findings are also supported by Sakatani et al. (2016), who found no relationship between estrus or non-estrus vaginal temperatures and walking activity in beef cows. When vaginal temperature and THI were both included as fixed effects in our statistical model, THI was a stronger risk factor for RI expression.

Our results and those of others (Verwoerd et al., 2006; Suthar et al., 2012) did not demonstrate a relationship between ambient temperature or THI and vaginal temperature. The lack of correlation between body and ambient temperature can be attributed to the large variation in individual temperature profiles among animals, likely caused by their ability to buffer against fluctuations in ambient temperature. Moreover, the confined and cross-ventilated design of the barn in this study ensured stable environmental conditions, which are not always found in studies conducted in tropical climates (Kendall et al., 2006). However, it is important to consider the possibility that air movement from the barn's ventilation system could increase convection currents surrounding the animal. Wind speed has been shown to influence environmental temperatures (Mader et al., 2006), and should be included in THI calculations when possible.

Our results showed that a lower THI is more conducive for dairy cows to express walking behavior at estrus compared with medium and high THI values. Environmental factors such as season, temperature, day length, and photoperiod have all been shown to influence estrus behavior in dairy cows (Orihuela, 2000). Our results are supported by Sakatani et al. (2012), who showed that average steps/hour of beef cows significantly decreased in the summer months compared with winter. Yániz et al. (2006) found that increases in mean relative humidity $>95 \%$ were associated with a decrease in walking activity at estrus. Moreover, LópezGatius et al. (2005) found that the increase in estrus activity was significantly lower in the warm period than in the cool period (369 \pm 152 vs. $384 \pm 156 \%$ relative increase, respectively). Based on recent findings, we speculate that the reduction in estrus behavior is multifactorial in nature and can be caused by increasing THI conditions, leading to reductions in DMI and altered dominant follicle profiles.

Relative increase of walking activity significantly increased $\mathrm{P} / \mathrm{AI}$ as cows that had high RI were 2.8 times more likely to be pregnant than animals that did not show a RI. Moreover, cows that exhibited high RI were 1.5 times more likely to become pregnant than low RI animals. Despite the lack of statistical significance, low PCT39 cows that displayed high RI had numerically higher P/AI compared with their high PCT39 counterparts. The protocol used in this experiment can increase plasma estradiol (E2) concentrations during the periovulatory period, which has been associated with improved $\mathrm{P} / \mathrm{AI}$ in heat-stressed cows (Pereira et al., 2013). Our results are supported by Madureira et al. (2015a), who found that cows with high estrus activity had a $35 \%$ improvement in fertility, and by López-Gatius et al. (2005), who reported an improvement in fertility for every unit increase in RI walking activity. Garcia et al. (2011) reported that high estrus intensity was associated with 4.6 to 4.8 higher odds of pregnancy and calving, respectively, compared with low or medium intensity walking behavior. Future studies could investigate the relationship between environmental and body temperatures and estrus behavior in cows exhibiting spontaneous estrus to determine potential differences in estrus behavior and body temperature associated with synchronization protocol enrollment. 
Cows that exhibit estrus at the moment of TAI and timed embryo transfer, respectively, have greater fertility and lower pregnancy loss compared with animals not in estrus (Cerri et al., 2004; Pereira et al., 2016). Animals that demonstrate more intense estrus have shorter intervals to ovulation (Van Eerdenburg et al., 2002), and low estrus expression leads to lower pregnancy per AI, more ovulation failure, and possibly TAI asynchrony (Madureira et al., 2015a,b; Burnett et al., 2017). Reames et al. (2011) suggest that the center in the hypothalamus responsible for behavioral estrus has a different activation threshold for estradiol compared with the center responsible for the LH surge. Therefore, at the end of a synchronization protocol, the amount of estradiol could be sufficient to induce a $\mathrm{GnRH}$ or LH surge but insufficient to induce behavioral estrus. The increased estradiol concentrations associated with behavioral estrus can enhance estrogen-dependent glycoproteins, which are responsible for increasing sperm transport and preparing the oviduct and uterine environment (Pereira et al., 2016).

Our results produced an interesting PCT39 $\times$ THI interaction. We showed that decreases in $\mathrm{P} / \mathrm{AI}$ were observed only in a subpopulation of cows with high PCT39 under high THI conditions. The negative effect of ambient temperature on pregnancy rate has been well documented. López-Gatius et al. (2005) found that insemination during the warm period led to a 0.8 -fold decrease in P/AI rate, and Morton et al. (2007) estimated that a daily maximum THI of 72 or more from d 35 before to d 6 after the day of breeding decreases conception rates of lactating dairy cows by $30 \%$. Even exposure to THI $\geq 73$ for $1 \mathrm{~h}$ on the day of breeding is sufficient to decrease the conception rate by $5 \%$, and pregnancy rates of Holsteins significantly decline from $28.5 \%$ under low THI $(<70)$ to $14.8 \%$ under high THI (>80) conditions (Schüller et al., 2014). Data from Demetrio et al. (2007) and Vasconcelos et al. (2011) also demonstrated that high body temperature measured on the day of embryo transfer had a negative effect on conception rates and embryonic retention. Despite the literature consensus, our results showed that even under high THI 9 to $11 \mathrm{~d}$ before breeding, a subgroup of cows exist that can thrive under these conditions and show similar pregnancy rates as cows who are under low heat load in low THI conditions. Pereira et al. (2013) found no difference for $\mathrm{P} / \mathrm{AI}$ in cows exposed to 1 bout of heat stress, or estrus cycle synchronization in animals exposed to 2 or more events of heat stress. The physiological mechanism behind maintaining high pregnancy rates under high THI conditions by sustaining low vaginal temperatures is unclear, and future research should aim to elucidate this relationship.

\section{CONCLUSIONS}

The relative increase in estrus walking behavior captured by an AAM at the time of induced estrus was correlated with BCS, DIM, and THI measured 9 to 11 d before RI, but not with PCT39, milk production, or parity. Parity, DIM, and RI were significant risk factors associated with P/AI. Cows that had more intense RI at estrus were significantly more fertile than cows with low intensity RI or no RI. An interaction was observed between PCT39 and THI, in that decreases in P/AI were only observed in cows with high PCT39 under high THI conditions. Information obtained from AAM systems can aid in estrus detection, improving $\mathrm{P} / \mathrm{AI}$ outcomes and enhancing the reproductive management of cows at risk for heat stress.

\section{ACKNOWLEDGMENTS}

We are grateful to Fazenda Colorado (Araras, Brazil) and their farm personnel for contributing to this research project. L. B. Polsky was supported by Mitacs Globalink Program (Ottawa, Canada), and the Natural Sciences and Engineering Research Council of Canada (Ottawa, Canada). We also thank CNPq-Science Without Borders program (Brasília, Brazil) for the funds provided to A. M. L. Madureira and E. L. Drago Filho. The authors also thank University of British Columbia students B. F. Silper and J. Luu, who assisted with data handling and analysis.

\section{REFERENCES}

Aungier, S. P. M., J. F. Roche, M. Sheehy, and M. A. Crowe. 2012. Effects of management and health on the use of activity monitoring for estrus detection in dairy cows. J. Dairy Sci. 95:2452-2466. https://doi.org/10.3168/jds.2011-4653.

Bates, D., M. Maechler, B. Bolker, and S. Walker. 2015. Fitting linear mixed-effects models using lme4. J. Stat. Softw. 67:1-48.

Burnett, T. A., A. M. L. Madureira, B. F. Silper, A. C. C. Fernandes, and R. L. A. Cerri. 2014. Effect of an automated estrous detection system during a timed artificial insemination program on first postpartum artificial insemination. J. Anim. Sci. 92(E-Suppl.):271. (Abstr.)

Burnett, T. A., A. M. L. Madureira, B. F. Silper, A. C. C. Fernandes, and R. L. A. Cerri. 2017. Integrating an automated activity monitor into an artificial insemination program and the associated risk factors affecting reproductive performance of dairy cows. J. Dairy Sci. 100:5005-5018.

Butler, W. R. 2000. Nutritional interactions with reproductive performance in dairy cattle. Anim. Reprod. Sci. 60-61:449-457. https:// doi.org/10.1016/s0378-4320(00)00076-2.

Butler, W. R. 2003. Energy balance relationships with follicular development, ovulation and fertility in postpartum dairy cows. Livest. Prod. Sci. 83:211-218. https://doi.org/10.1016/s0301 -6226(03)00112-x.

Cerri, R. L. A., J. E. P. Santos, S. O. Juchem, K. N. Galvão, and R. C. Chebel. 2004. Timed artificial insemination with estradiol cypionate or insemination at estrus in high-producing dairy cows. 
J. Dairy Sci. 87:3704-3715. https://doi.org/10.3168/jds.s0022 -0302(04)73509-2.

De Rensis, F., and R. J. Scaramuzzi. 2003. Heat stress and seasonal effects on reproduction in the dairy cow-A review. Theriogenology 60:1139-1151. https://doi.org/10.1016/s0093-691x(03)00126-2.

Demetrio, D. G. B., R. M. Santos, C. G. B. Demetrio, and J. L. M. Vasconcelos. 2007. Factors affecting conception rates following artificial insemination or embryo transfer in lactating Holstein cows. J. Dairy Sci. 90:5073-5082. https://doi.org/10.3168/jds.2007 $-0223$

FASS. 1999. Guide for the care and use of agricultural animals in agricultural research and teaching. 1st rev. ed. Federation of Animal Science Societies, Savoy, IL.

Frank, E. H., Jr., and C. Dupont. 2016. Hmisc: Harrell Miscellaneous. $\mathrm{R}$ package version 4.0-0. https://CRAN.R-project.org/package= Hmisc.

Garcia, E., J. Hultgren, P. Fällman, J. Geust, B. Algers, G. Stilwell, S. Gunnarsson, and H. Rodriguez-Martinez. 2011. Oestrous intensity is positively associated with reproductive outcome in high-producing dairy cows. Livest. Sci. 139:191-195. https://doi.org/10.1016/ j.livsci.2011.01.004.

Gwazdauskas, F. C., W. W. Thatcher, and C. J. Wilcox. 1973. Physiological, environmental, and hormonal factors at insemination which may affect conception. J. Dairy Sci. 56:873-877. https://doi .org/10.3168/jds.S0022-0302(73)85270-1.

IPCC (Intergovernmental Panel on Climate Change). 2007. Summary for policy makers. Page 23. Cambridge Press, Cambridge, UK.

Kadzere, C. T., M. R. Murphy, N. Silanikove, and E. Maltz. 2002. Heat stress in lactating dairy cows: a review. Livest. Prod. Sci. 77:59-91. https://doi.org/10.1016/s0301-6226(01)00330-x.

Kendall, P. E., P. P. Nielsen, J. R. Webster, G. A. Verkerk, R. P Littlejohn, and L. R. Matthews. 2006. The effects of providing shade to lactating dairy cows in a temperate climate. Livest. Sci 103:148-157. https://doi.org/10.1016/j.livsci.2006.02.004.

López-Gatius, F., P. Santolaria, I. Mundet, and J. L. Yániz. 2005. Walking activity at estrus and subsequent fertility in dairy cows. Theriogenology 63:1419-1429. https://doi.org/10.1016/j .theriogenology.2004.07.007.

Løvendahl, P., and M. G. G. Chagunda. 2010. On the use of physical activity monitoring for estrus detection in dairy cows. J. Dairy Sci. 93:249-259.

Mader, T. L., M. S. Davis, and T. Brown-Brandl. 2006. Environmental factors influencing heat stress in feedlot cattle. J. Anim. Sci 84:712-719. https://doi.org/10.2527/2006.843712x.

Madureira, A. M. L., B. F. Silper, T. A. Burnett, L. Polsky, L. H. Cruppe, D. M. Veira, J. L. M. Vasconcelos, and R. L. A. Cerri. 2015a. Factors affecting expression of estrus measured by activity monitors and conception risk of lactating dairy cows. J. Dairy Sci. 98:7003-7014. https://doi.org/10.3168/jds.2015-9672.

Madureira, A. M. L., B. F. Silper, T. A. Burnett, L. B. Polsky, E. L. Drago Filho, S. Soriano, A. F. Sica, J. L. M. Vasconcelos, and R. L. A. Cerri. 2015b. Effects of expression of estrus measured by activity monitors on ovarian dynamics and conception risk in Holstein cows. J. Dairy Sci. 98(Suppl. 1):875. (Abstr.)

Morton, J. M., W. P. Tranter, D. G. Mayer, and N. N. Jonsson. 2007. Effects of environmental heat on conception rates in lactating dairy cows: Critical periods of exposure. J. Dairy Sci. 90:22712278. https://doi.org/10.3168/jds.2006-574.

NRC. 2001. Nutrient Requirements of Dairy Cattle. 7th rev. ed. National Academies Press, Washington, DC.

Orihuela, A. 2000. Some factors affecting the behavioural manifestation of oestrus in cattle: A review. Appl. Anim. Behav. Sci. 70:116. https://doi.org/10.1016/s0168-1591(00)00139-8.

Peralta, O. A., R. E. Pearson, and R. L. Nebel. 2005. Comparison of three estrus detection systems during summer in a large commercial dairy herd. Anim. Reprod. Sci. 87:59-72. https://doi.org/10 $.1016 /$ j.anireprosci.2004.10.003.

Pereira, M. H. C., A. D. P. Rodrigues, T. Martins, W. V. C. Oliveira, P. S. A. Silveira, M. C. Wiltbank, and J. L. M. Vasconcelos. 2013. Timed artificial insemination programs during the summer in lactating dairy cows: Comparison of the 5-d Cosynch protocol with an estrogen/progesterone-based protocol. J. Dairy Sci. 96:69046914. https://doi.org/10.3168/jds.2012-6260.

Pereira, M. H. C., M. C. Wiltbank, L. F. S. P. Barbosa, W. M. Costa, M. A. P. Carvalho, and J. L. M. Vasconcelos. 2015. Effect of adding a gonadotropin-releasing-hormone treatment at the beginning and a second prostaglandin $\mathrm{F}_{2 \alpha}$ treatment at the end of an estradiol-based protocol for timed artificial insemination in lactating dairy cows during cool or hot seasons of the year. J. Dairy Sci. 98:947-959. https://doi.org/10.3168/jds.2014-8523.

Pereira, M. H. C., M. C. Wiltbank, and J. L. M. Vasconcelos. 2016. Expression of estrus improves fertility and decreases pregnancy losses in lactating dairy cows that receive artificial insemination or embryo transfer. J. Dairy Sci. 99:2237-2247. https://doi.org/10 $.3168 /$ jds.2015-9903.

R Core Team. 2016. R: A language and environment for statistical computing. Foundation for Statistical Computing, Vienna, Austria. http://www.R-project.org/.

Reames, P. S., T. B. Hatler, S. H. Hayes, D. L. Ray, and W. J. Silvia. 2011. Differential regulation of estrous behavior and luteinizing hormone secretion by estradiol-17 $\beta$ in ovariectomized dairy cows. Theriogenology 75:233-240.

Roelofs, J., F. López-Gatius, R. H. F. Hunter, F. J. C. M. Van Eerdenburg, and C. Hanzen. 2010. When is a cow in estrus? Clinical and practical aspects. Theriogenology 74:327-344. https://doi.org/10 $.1016 /$ j.theriogenology.2010.02.016

Roelofs, J. B., F. J. van Eerdenburg, N. M. Soede, and B. Kemp. 2005. Pedometer readings for estrous detection and as predictor for time of ovulation in dairy cattle. Theriogenology 64:1690-1703. https:// doi.org/10.1016/j.theriogenology.2005.04.004.

Roth, Z., R. Meidan, R. Braw-Tal, and D. Wolfenson. 2000. Immediate and delayed effects of heat stress on follicular development and its association with plasma FSH and inhibin concentration in cows. J. Reprod. Fertil. 120:83-90. https://doi.org/10.1530/reprod/120 .1 .83

Sakatani, M., A. Z. Balboula, K. Yamanaka, and M. Takahashi. 2012. Effect of summer heat environment on body temperature, estrous cycles and blood antioxidant levels in Japanese Black cow. Anim. Sci. J. 83:394-402. https://doi.org/10.1111/j.1740-0929.2011 $.00967 . x$.

Sakatani, M., M. Takahashi, and N. Takenouchi. 2016. The efficiency of vaginal temperature measurement for detection of estrus in Japanese Black cows. J. Reprod. Dev. 62:201-207. https://doi.org/10 $.1262 /$ jrd.2015-095.

Schüller, L. K., O. Burfeind, and W. Heuwieser. 2014. Impact of heat stress on conception rate of dairy cows in the moderate climate considering different temperature-humidity index thresholds, periods relative to breeding, and heat load indices. Theriogenology 81:1050-1057. https://doi.org/10.1016/j.theriogenology.2014.01 .029 .

Schütz, K. E., N. R. Cox, and L. R. Matthews. 2008. How important is shade to dairy cattle? Choice between shade or lying following different levels of lying deprivation. Appl. Anim. Behav. Sci. 114:307-318. https://doi.org/10.1016/j.applanim.2008.04.001.

Silper, B. F., I. Robles, A. M. L. Madureira, T. A. Burnett, M. M. Reis, A. M. de Passillé, J. Rushen, and R. L. A. Cerri. 2015. Automated and visual measurements of estrous behavior and their sources of variation in Holstein heifers. I: Walking activity and behavior frequency. Theriogenology 84:312-320. https://doi.org/ 10.1016/j.theriogenology.2014.12.029.

St-Pierre, N. R., B. Cobanov, and G. Schnitkey. 2003. Economic losses from heat stress by US livestock industries. J. Dairy Sci. 86:E52E77. https://doi.org/10.3168/jds.S0022-0302(03)74040-5.

Stevenson, J. S., S. L. Hill, R. L. Nebel, and J. M. DeJarnette. 2014 Ovulation timing and conception risk after automated activity monitoring in lactating dairy cows. J. Dairy Sci. 97:4296-4308. https://doi.org/10.3168/jds.2013-7873.

Suthar, V. S., O. Burfeind, S. Bonk, A. J. Dhami, and W. Heuwieser 2012. Endogenous and exogenous progesterone influence body temperature in dairy cows. J. Dairy Sci. 95:2381-2389. https://doi .org/10.3168/jds.2011-4450. 
Thatcher, W. W., and R. J. Collier. 1986. Effects of climate on bovine reproduction. Curr. Ther. Theriogenol. 2:301-309.

Van Eerdenburg, F. J. C. M., D. Karthaus, M. A. M. Taverne, I. Mercis, and O. Szenci. 2002. The relationship between estrous behavioral score and time of ovulation in dairy cattle. J. Dairy Sci. 85:1150-1156. https://doi.org/10.3168/jds.S0022-0302(02)74177 -5 .

Vasconcelos, J. L. M., R. F. Cooke, D. T. G. Jardina, F. L. Aragon, M. B. Veras, S. Soriano, N. Sobreira, and A. B. Scarpa. 2011. Associations among milk production and rectal temperature on pregnancy maintenance in lactating recipient dairy cows. Anim. Reprod. Sci. 127:140-147. https://doi.org/10.1016/j.anireprosci.2011.07.012.

Verwoerd, W., M. Wellby, and G. Barrell. 2006. Absence of a causal relationship between environmental and body temperature in dairy cows (Bos taurus) under moderate climatic conditions. J. Therm. Biol. 31:533-540. https://doi.org/10.1016/j.jtherbio.2006.07.001.

Walsh, S. W., E. J. Williams, and A. C. O. Evans. 2011. A review of the causes of poor fertility in high milk producing dairy cows.
Anim. Reprod. Sci. 123:127-138. https://doi.org/10.1016/j .anireprosci.2010.12.001.

West, J. W. 2003. Effects of heat-stress on production in dairy cattle. J. Dairy Sci. 86:2131-2144. https://doi.org/10.3168/jds.S0022 $-0302(03) 73803-x$

Wildman, E. E., G. M. Jones, P. E. Wagner, R. L. Boman, H. F. Troutt, and T. N. Lesch. 1982. A dairy cow body condition scoring system and its relationship to selected production characteristics. J. Dairy Sci. 65:495-501. https://doi.org/10.3168/jds.s0022 -0302(82)82223-6.

Wolfenson, D., Z. Roth, and R. Meidan. 2000. Impaired reproduction in heat-stressed cattle: Basic and applied aspects. Anim. Reprod. Sci. 60-61:535-547. https://doi.org/10.1016/s0378-4320(00)00102 $-0$.

Yániz, J. L., P. Santolaria, A. Giribet, and F. López-Gatius. 2006. Factors affecting walking activity at estrus during postpartum period and subsequent fertility in dairy cows. Theriogenology 66:19431950. https://doi.org/10.1016/j.theriogenology.2006.05.013. 